\title{
Oral Health status of 3-6 year old children and their mother's oral health related knowledge, attitude and practices in Mysore City, India
}

\author{
Darshana Bennadi ${ }^{1}$, C.V.K. Reddy ${ }^{2}$, S. Sunitha ${ }^{3}$, Nandita Kshetrimayum ${ }^{4}$ \\ ${ }^{1}$ Reader, Dept. of Public Health Dentistry, Sree Siddhartha Dental College and Hospital, Tumkur, India, ${ }^{2}$ Professor and Head, Dept. of \\ Public Health Dentistry, J S S Dental College and Hospital, Mysore, India, ${ }^{3}$ Reader, Dept. of Public Health Dentistry, J S S Dental College \\ and Hospital, Mysore, India, ${ }^{4}$ Assistant Professor, Dept. of Public Health Dentistry, Regional Institute of Medical sciences, Dental College, \\ Lamphelpat, Imphal, West Manipur, India
}

\section{A B S T R A C T}

Aims and Objectives: The study was carried out to assess oral health status of 3-6 year old children and their mother's oral health related knowledge, attitude and practices in Mysore city. Moreover, this study also carried out to determine whether mother's oral health related knowledge, attitude and practices influences oral health of their children. Materials and Methods: A total of 500 children belonging to the age group of 3-6 years old attending both governments sponsored and private preschools from five sectors accompanied by their mothers formed the study group. Oral health status was assessed by using decayed missing filled teeth index (dmft) and plaque index. Mother's knowledge, attitude and practices were assessed by direct contact with mothers using closed ended questionnaire. Results: The results of the study showed that the prevalence of dental caries among children was $64 \%$ with mean dmft of $3.20 \pm 3.08$ and mean plaque scores was $0.87 \pm 0.33$. There was significant correlation between plaque scores and $\mathrm{dmft}$. $\mathrm{dmft}$ and plaque score was higher in older individuals and the difference was highly significant. Mean plaque score was more among the government preschool children (1.02 \pm 0.31$) .46 \%$ of mothers had medium level knowledge, $63.2 \%$ mothers had average attitude and $51 \%$ mothers had high level practices related to oral health. An inverse relationship was found between mean $\mathrm{dmft}$, caries prevalence, mean plaque score in children and mother's knowledge, attitude and practices about oral health and the findings were highly significant. Conclusion: Results showed that mother's oral health related knowledge; attitude and practices had influence on oral health status of their children

Key words: Attitude, Caries, Knowledge, Plaque, Practice, Preschool, Mothers, dmft

\section{INTRODUCTION}

"Make every mother and child count" was the World Health Day theme for the year 2005. ${ }^{1}$ They count because we value every human life. The healthy mothers and children are the bedrock of healthy and prosperous communities and nations. Effective knowledge and tools exist to reduce suffering and death. However; we must reach all mothers and children who need them to make a real difference. Health has been declared a fundamental human right. Oral health is an integral part of general health, rather oral cavity can rightly be called gateway of the body.
The health of the mouth and dentition plays a major role in the life of the child, through facilitating nutritional intake, providing a non verbal means of expressing happiness and sadness and allowing for vocal communication. Therefore, a healthy mouth with a full complement of teeth should be the goal for all children. ${ }^{2}$

One of the goals set by WHO for oral health was that by the year 2000; $50 \%$ of 5-6 years old children should be caries free. Oral epidemiological surveys conducted in selected areas in Guangdong Province in 1987-1992 showed that the caries prevalence among preschool children was 
from $80-90 \%{ }^{3}$ For young children, parents or the family represents the primary source of information about oral health. One way to increase children's oral health awareness would be to give accurate information to parents. ${ }^{4}$

A young child's dental environment is complex because their mother's dental knowledge, attitude and practices affect the child's oral condition. Few studies have shown that there is influence of mothers' oral health-related knowledge and attitudes on the tooth-brushing behaviour and dental health of their children. ${ }^{5}$ Conditions established in preschool years provide a foundation for oral health and patterns for the use of dental services later and in adulthood. Parents need to be helped to realize that they are role models for their children and to be encouraged to improve the children's dental health habits.

There is very little literature regarding the influence of mother's oral health related knowledge, attitude and practices on their child's oral health in India. Hence, an attempt was made to undertake this study.

\section{MATERIALS AND METHODS}

This descriptive cross sectional study was conducted for a period of six months among the preschool children and their mothers in Mysore city. The ethical clearance was obtained from the ethical committee of J.S.S. Dental College and Hospital, Mysore, India. The permission to carry out this study was taken from the school authorities and parents of the participating children before examination. The pilot study helped in assessing the sample size and validity of questionnaire. The children attending both government and private preschools belonging to the age group of 3-6 years who were accompanied by their mothers formed the study group and selected on the basis of stratified random sampling technique. As per the Child Development Project Officer (CDPO), Mysore city is divided into five sectors; N.R. Mohalla, Mandi Mohalla, Chamaraj Mohalla, Devaraj Mohalla and Kyathamaranhalli. 50 government and 50 private preschool children were selected randomly, thus making a total sample size of 500 .

\section{Questionnaire part}

Mother's knowledge, attitude and practices were assessed by direct contact with mothers using questionnaire that was designed in both English and Kannada and which included,

I. General information: About their Education, socioeconomic status, etc.

II. Knowledge: Oral health related knowledge like causes and prevention of dental caries and gum disease, dietary habits mainly about sugar consumption and fluoride, sources of dental health information and their perception of prosthetic appliances, malocclusion etc. III. Attitude: Attitude towards the prevention of oral diseases, dental visits, and importance of milk teeth, etc. and to rate the extent of their agreement and disagreement on the statements using three point Likert type scale.

IV. Practices: Oral hygiene practices mainly brushing and rinsing habits, dental visiting habits, services received at the last visit, mothers support in oral health, etc.

\section{Oral examination of children}

The child was made to sit comfortably on the chair and clinical examination was carried out with mouth mirror, explorer under natural light (ADA Type 3 examination method). The instruments were sterilized chemically. Caries status was assessed by using $\mathrm{dmft}$ index ${ }^{6}$ (WHO criteria 1999 for dental caries) ${ }^{7}$ and oral hygiene was assessed by plaque index (Sillness and Loe, 1964). ${ }^{8}$ Investigator underwent training and calibration and agreement for the assessment was 90 percent.

A total of 500; 3-6 years old children who were accompanied by their mothers and whose general health was within normal limits were included.

\section{Socioeconomic status}

It was done on the basis of the modified B.G Prasad's classification $1961^{\circ}$ for the year 2007. Consumer price index for urban workers as per 2007 is 541 and the modifying factor/percent change is 6.90. (Source: Reserve Bank of India, Government of India) (Table 1).

\section{Statistical analysis}

The collected data was subjected for statistical analysis using SPSS version 16. The various parameters were arithmetic mean, standard deviation, standard error, t-test and chi-square test, $\mathrm{F}$ test, contingency coefficient and Pearson correlation test. The $\mathrm{p}$ value of $<0.05$ was taken as statistically significant. For the purpose of analysis, the individual scores were summed up to yield a total score. The mean of the scores were obtained and an ordinal scale was developed such as for the knowledge: Low, Medium and High; for the attitude: Unfavourable, Average and Favourable; and for the practices: Less, Moderate and High.

\begin{tabular}{ll}
$\begin{array}{l}\text { Table 1: Modified classification for the present } \\
\text { socioeconomic status (SES) }\end{array}$ \\
\hline Per capita family income (Rs.) & SES category \\
\hline 3697 and above & Upper class \\
$1830-3696$ & Upper middle \\
$1084-1829$ & Lower middle \\
$560-1083$ & Upper lower \\
Less than 560 & Lower class \\
\hline
\end{tabular}




\section{RESULTS}

Among total of $500(100 \%)$ children in the study group, $18 \%(\mathrm{n}=90)$ were 3 years old, $28.4 \%(\mathrm{n}=142)$ were 4 years old, $31.4 \%(n=157)$ were 5 years old and $22.2 \%(n=111)$ were 6 years old. $53.2 \%(\mathrm{n}=266)$ were male and $46.8 \%$ $(\mathrm{n}=234)$ were female.

The mean dt (decayed teeth) was $2.68 \pm 2.8$, mean $\mathrm{mt}$ (missing teeth) was $0.23 \pm 0.8$, mean $\mathrm{ft}$ (filled teeth) was $0.28 \pm 0.89$ and mean dmft was $3.20 \pm 3.0$. Interarch analysis of the caries attack was $60.8 \%(n=304 / 500)$ for the maxillary arch and 59.4\% ( $\mathrm{n}=297 / 500)$ were for the mandibular arch.

Among five sectors, the mean $\mathrm{dmft}$ and mean plaque score values of Kyathamaranhalli preschool children differed significantly from Chamaraj Mohalla, Mandi Mohalla and Devaraj Mohalla sectors (Table 2).

The mean $\mathrm{dmft}$ and mean plaque score was high among government preschool children compared to private school children which was statistically highly significant (Table 3).

The mean dmft was $3.46 \pm 3.1$ in male, $2.91 \pm 2.9$ in female children and it was statistically significant. As the age of child increased, the mean $\mathrm{dmft}$ and mean plaque scores increased which was highly significant.

An inverse relationship was found between caries status, oral hygiene status of children and education as well as socioeconomic status of mothers. The Karl Pearson coefficient between plaque scores and $\mathrm{dmft}$ values was 0.650 which was highly significant $(p<0.001)$. Significant

\begin{tabular}{|c|c|c|c|}
\hline Sectors & $\begin{array}{l}\text { No. of } \\
\text { children }\end{array}$ & $\begin{array}{c}\text { dmft } \\
\text { Mean } \pm S D\end{array}$ & $\begin{array}{c}\text { Plaque score } \\
\text { Mean } \pm S D\end{array}$ \\
\hline Chamaraj Mohalla & 100 & $3.17 \pm 3.19$ & $0.94 \pm 0.28$ \\
\hline N.R. Mohalla & 100 & $3.34 \pm 2.91$ & $0.71 \pm 0.30$ \\
\hline Mandi Mohalla & 100 & $2.35 \pm 2.37$ & $0.93 \pm 0.21$ \\
\hline Kyathamaranhalli & 100 & $4.53 \pm 3.30$ & $1.11 \pm 0.32$ \\
\hline Devaraj Urs Mahalla & 100 & $2.62 \pm 3.10$ & $0.67 \pm 0.34$ \\
\hline Total & 500 & $3.20 \pm 3.08$ & $0.87 \pm 0.33$ \\
\hline$p$-value & & $0.001(\mathrm{HS})$ & $0.001(\mathrm{HS})$ \\
\hline
\end{tabular}

positive correlation was observed between children with fillings and knowledge scores where correlation coefficient equals to 0.239 is found to be highly significant at $\mathrm{p}<0.001$ level. As the scores in filling increased, scores in knowledge also increased linearly and vice versa.

Most of the mothers got information about dental health through television, dentist and relatives and friends (Graph 1).

Regarding the overall knowledge, $45 \%$ of mothers had low level of knowledge, $46 \%$ of them had medium level of knowledge and 9\% of them had high level of knowledge. Maximum number of mothers having low level of knowledge was found in Kyathamaranhalli (61\%) and government school.

Regarding overall attitude, $2 \%$ of the mothers had unfavourable attitude, $63.2 \%$ had average attitude and $34.8 \%$ had favourable attitude. Unfavourable attitude was found more among mothers in Mandi Mohalla (5\%) and mothers of government.

Regarding the overall practices, $7.2 \%$ of mothers had less level of practices, $41.8 \%$ had moderate level of practices and $51 \%$ had high level of practices. Maximum number of mothers having less level of practices was found in Kyathamaranhalli (14\%) and of government preschool $(62.8 \%)$.

An inverse relationship was found between mean dmft; mean plaque scores in children and mothers knowledge, attitude and practices about oral health which was highly significant.

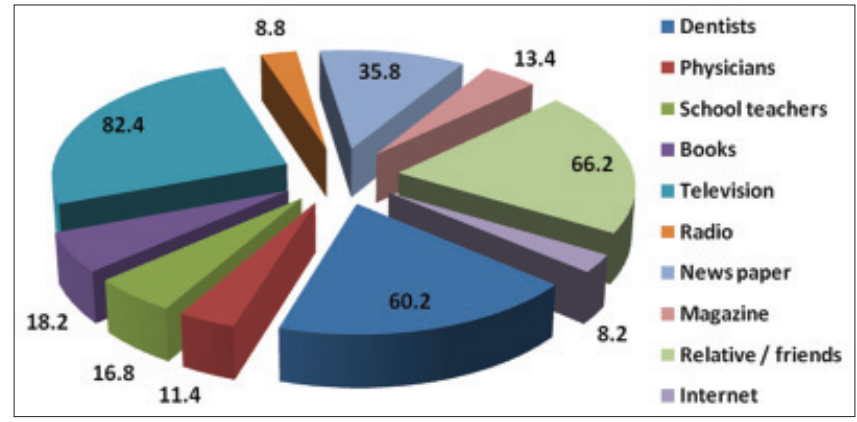

Graph 1: Distribution of mothers based on source of information

\begin{tabular}{|c|c|c|c|c|c|c|}
\hline \multirow{2}{*}{$\begin{array}{l}\text { Type of } \\
\text { preschool }\end{array}$} & \multirow[t]{2}{*}{ No. } & Decayed & Missing & Filled & Dmft & \multirow{2}{*}{$\begin{array}{l}\text { Plaque score } \\
\text { Mean } \pm S D\end{array}$} \\
\hline & & Mean $\pm S D$ & Mean $\pm S D$ & Mean $\pm S D$ & Mean $\pm S D$ & \\
\hline Private & 250 & $1.66 \pm 2.30$ & $0.02 \pm 0.45$ & $0.56 \pm 1.19$ & $2.32 \pm 2.58$ & $0.73 \pm 0.31$ \\
\hline Government & 250 & $3.70 \pm 2.93$ & $0.37 \pm 1.05$ & $0.00 \pm 0.00$ & $4.08 \pm 3.28$ & $1.02 \pm 0.31$ \\
\hline$p$-value & & \multicolumn{4}{|c|}{$0.001(\mathrm{HS})$} & $0.001(\mathrm{HS})$ \\
\hline
\end{tabular}

HS=Highly significant 


\section{DISCUSSION}

Despite the widespread preventive measures, dental caries continues to be a scourge for mankind even today. This disease exerts a social, physical, mental and financial burden on a global scale, with developing countries being affected the most. Parents of preschool children are the primary decision makers regarding their children's health related behaviours and health care who can shape children's behavior by means of selectively encouraging and discouraging particular habits.

Children of age group 3-6 years were selected because it will be difficult to get the cluster of sample at a common place below 3 years of children, uncooperative behaviour of such young children, difficulty in detailed examination of the oral cavity and varied number of teeth erupted in very young children.

Prevalence of dental caries in the present study of 3-6 years old preschool children was $64 \%$. A similar trend of caries was reported in Brazil (46\%), ${ }^{10}$ Kerala (57\%), ${ }^{11}$ Guangxi Province in China (55\%), ${ }^{12}$ Dharwad $(54.1 \%)^{13}$ and Latino Americans (46\%). ${ }^{14}$ Trends of higher caries were reported in other studies in preschool children of China $(83 \%),{ }^{15}$ Moodbidri (76.9\%), ${ }^{16}$ Ajman $(76.1 \%),{ }^{17}$ Riyadh (74.8\%) ${ }^{18}$

Maximum decayed component and very negligible filled component was observed. Similar values were found in earlier studies conducted in North and West Belfast $(2.36 \mathrm{dt}, 0.41 \mathrm{ft}) .{ }^{19}$ Mean dt was found higher in Riyadh preschool children $(4.66)^{18}$ compared to our study. Decayed component making the major component of $\mathrm{dmft}$ score suggests the large unmet treatment needs. This may be due to lack of oral awareness in parents, unhealthy feeding habits and oral hygiene practices, high cost of dental treatment and limited accessibility and availability of dental services.

In our study, the mean $\mathrm{dmft}$ was $3.20 \pm 3.0$ with highest decayed component (dt) $2.68 \pm 2.8$. Similar $\mathrm{dmft}$ values were observed in earlier studies conducted in Pelotas, Brazil (3.20), ${ }^{20}$ Moodbidri (3.48), ${ }^{16}$ Chandigarh (4.0), ${ }^{21}$ North and West Belfast (3.81), ${ }^{19}$ Hubli-Dharwad (2.70 33.57$),{ }^{13}$ Ajman (4.4), ${ }^{17}$ and Kerala $(2.5 \pm 0.96) .{ }^{11}$

Higher $\mathrm{dmft}$ values were found in studies conducted among preschool children of Glasgow (7.9), ${ }^{22}$ Riyadh $(6.1),{ }^{18}$ China $(6.1 \pm 4.7)^{15}$ and Wuhan China Urban (5.7). ${ }^{23}$ The dmft value in our study was higher than the values reported by earlier studies of Herdfordshire (0.37). ${ }^{18,24,25}$ This difference in the caries prevalence and mean dmft may be due to different levels of preventive measures practiced in these places and due to different environmental, social and cultural differences prevalent at different places.
Interarch analysis, comparing teeth of maxillary and mandibular arch revealed that both were equally affected. The results are not in agreement with the study carried out in Kerala in 2003, ${ }^{11}$ Riyadh in $2008^{18}$ and China. ${ }^{12}$ Mandibular anterior were the least commonly affected teeth $(10.4 \%)$. This is in agreement with studies conducted in Riyadh $^{18}$ and China. ${ }^{12}$ This might be due to the reason that lower incisors are prevented from direct exposure during intake of acidic drinks by the tongue and salivary flow from sublingual ducts which dilutes the acidic environment around the tooth.

Government preschool children showed higher caries prevalence and mean plaque scores compared to private preschool children. Filled component was more among private preschool children compared to government preschool children. Similar results were seen in study conducted in Riyadh in 2008, ${ }^{18}$ Goiânia-GO, Brazil 1996. ${ }^{26}$ Children from higher socioeconomic strata go to private preschools and their parents are better educated and in better position to be more conscious of or concerned about the diet and oral hygiene of their children.

There was no statistically significant difference in the prevalence of dental caries among males and females. Similar findings were found in China,${ }^{15}$ Riyadh, ${ }^{18}$ Manchester, ${ }^{27}$ Hubli-Dharwad, ${ }^{13}$ Ajman ${ }^{17}$ and Mangalore. ${ }^{28}$ The results of the present study are not in agreement with the earlier studies in Pelotas, Brazil. ${ }^{20}$ Males had higher $\mathrm{dmft}$ than females. Similar results were found in preschool children of Moodbidri. ${ }^{16}$ Findings of our study are not in agreement with earlier studies conducted in Herdfordshire, ${ }^{24}$ Abudhabi and Al Ain. ${ }^{29}$ Dietary and oral hygiene practices related to dental caries are mostly controlled by parents or caretakers at this early age. As a result it may be too early to develop any gender difference. They attributed this difference to diet, geographical location and cultural differences seen in some societies where males are given more priority.

In our study, we found highly significant association between age of the children and caries prevalence and it was in agreement with studies of Wyne A H et al. ${ }^{18}$ Douglass JM, ${ }^{30,31}$ America Segovia-Villanueva, ${ }^{32}$ Khan $\mathrm{MN}^{33}$ and Watson M R. ${ }^{14}$ Whereas, study conducted by Rao $\mathrm{A}^{16}$ was not in agreement with our study. It might be due to the fact that parents won't be assisting as the children grow older; lack of proper muscle coordination to brush, eruption of permanent teeth might lead to accumulation of plaque and change in diet which might lead to dental caries.

As education of mothers increased, their children showed good oral health status. It was similar to studies conducted by Hashim $\mathrm{R}$ et al, ${ }^{17} \mathrm{P}$ Sudha, ${ }^{28}$ Eissa Al-Hosani et al, ${ }^{29}$ 
Khan MN, ${ }^{33}$ Rao A, ${ }^{16}$ S.C.L. Chan,,${ }^{5}$ R.S. Naidu, ${ }^{34}$ Franciszek Szatko, ${ }^{35}$ Babu Jose. ${ }^{11}$ Statistically significant difference was found between mother's education status and her knowledge about oral health. The finding was in agreement with studies conducted in Poland ${ }^{35,36}$ and Burnley, Pendle and Rossendale. ${ }^{37}$ Improved level of education may be able to access appropriate sources of information and understand that information more fully.

Children of lower socioeconomic class showed higher caries prevalence and mean plaque score. Similar finding were found in Trinidadian, ${ }^{34}$ Riyadh,${ }^{18}$ China,${ }^{15}$ Africa, ${ }^{27}$ Davangere ${ }^{38}$ and Kerala. ${ }^{11,39}$ Individual from lower socioeconomic class experience financial, social and material disadvantages that compromise their ability to care for themselves, obtain professional health services and live in a healthy environment; all of which lead to reduce resistance to oral and other diseases. Low family income may affect food selection and nutrient intake. The findings of our study are not in agreement with studies conducted in Abu Dhabi. ${ }^{29}$ Caries prevalence was lower in children coming from low income category and the reason they noted is that there is limited intake of sugar containing snacks and caries prevalence was high in high socioeconomic child due to frequent intake of sugar containing milk and calorigenic snacks.

A statistically significant association was found between caries prevalence and plaque score which was in agreement with studies conducted in Kerala ${ }^{39}$ and Mangalore..$^{28}$

Statistically significant association was found between mother's knowledge about oral health along with her education level and socioeconomic status. Similar finding were seen in studies of Wierzbicka $\mathrm{M}^{36} \mathrm{~N}$. J. Williams ${ }^{37}$ and Szatko F. ${ }^{35}$ Improved level of education may be able to access appropriate sources of information and understand that information completely. Statistical significant association was seen between mother's knowledge, attitude, practices about oral health and caries prevalence, mean $\mathrm{dmft}$ and plaque score. Similar results were found in studies conducted among mothers of Poland ${ }^{35,36}$ and Burnley, Pendle and Rossendale. ${ }^{37}$

Parents are the caretakers of the child. The children's preventive practices tend to be controlled by their parent's knowledge, attitude and practices. A low level of awareness of oral health among the parents will ultimately reflect on child's oral health.

Limitation of this study was non cavitated lesions; malocclusion status was not recorded and children younger than 3 years were not included. So, further studies should be conducted in this regard.

\section{CONCLUSION}

Present study results showed that mother's oral health related knowledge; attitude and practices have influence on the oral health status of their children. So, health education should focus on parental responsibility for oral health and the mothers and teachers of child care centers should be encouraged to give practical and emotional support to their children with regard to oral hygiene habits. Providing tooth paste and toothbrushes through sponsors, government operated ration shops and should be made available at subsidized prices. Television means can be used to impart more oral health related knowledge. Yashashwini plan should also include preventive dental treatment facility. Oral counselling should begin within 6 months of eruption of the $1^{\text {st }}$ primary tooth.

\section{REFERENCES}

1. 'Make every mother and child counf'- World Health Day theme 2005. Accessed from: http;//an advocacy toolkit WHO. [last accessed on 9/11/2007].

2. Erickson RT and Thomas HF. A survey of the American Academy of Pediatric dentistry membership infant oral health care. Pediatr Dent: 1997; 19(1): 17-21.

3. Wong MCM, Lol ECM, Schwarz' E and Zhang HG. Oral health status and oral health behaviours in Chinese children. J Dent Res 2001; 80(5): 1459-1465.

4. Poul EP, Danila I and Samoila A. Oral health behaviour, knowledge and attitudes of children, mothers and school teachers in Romania in 1993. Acta Odontol Scand: 1995; 53: 363-368.

5. Chan SCL, Tsai JSJ, and King NM. Feeding and oral hygiene habits of preschool children in Hong Kong and their caregivers' dental knowledge and attitudes. Int J Paediatr Dent 2002 Sep; 12(5): 322-331.

6. Gruebbel AO. Measurement of dental caries prevalence and treatment service for deciduous teeth. J Dent Res1944; 23: 163168.

7. World Health Oraganization. Oral health surveys - Basic methods. $4^{\text {th }}$ ed. Geneva; World Health Organization; 1999.

8. Loe $\mathrm{H}$. The gingival index, the plaque index and their retention system. J Periodontal 1967; 38: 610-616.

9. Chandra S. Sociology and health essentials of community medicine. Ist Edition, 75-79.

10. Dini EL, Holt RD and Bedi J. Caries and its association with infant feeding and oral health - related behavior in 3-4 year old Brazilian children. Community Dent Oral Epidemiol 2000; 28: 241- 248.

11. Kuriakose $S$ and Joseph $E$. Caries prevalence and its relation to socio-economic status and oral hygiene practices in 600 preschool children of kerala-India. J Indian Soc Pedo Prev Dent 1999; 17(3): 97-100.

12. Du M, Luo Y, Zeng $X$, Alkhatib $N$ and Bedi R. Caries in preschool children and its risk factors in 2 provinces in China. Quintessence Int 2007; 38(2): 143-151.

13. Mahejabeen R, Sudha P, Kulkarni SS and Anegundi R. Dental caries prevalence among preschool children of Hubli: Dharwad city. J Indian Soc Pedod Prev Dent 2006; 3: 19-22.

14. Watson MR, Horowitz AM, Garcia I and Canto MT. Caries conditions among 2-5-year-old immigrant Latino children related 
to parents' oral health knowledge, opinions and practices. Community Dent Oral Epidemiol 1999 Feb; 27(1): 8-15.

15. Li $Y$ and Wang W. Predicting Caries in Permanent Teeth from Caries in Primary Teeth: An Eight-year Cohort Study. J Dent Res 2002; 81(8): 561-566.

16. Rao A, Sequeira SP and Peter S. Prevalence of dental caries among school children of Moodbidri. J Indian Soc Pedo Prev Dent 1999; 17(2): 45-48.

17. Hashim R, Thomson WM, Ayers KMS, Lewsey JD and Awad M. Dental caries experience and use of dental services among preschool children in Ajman, UAE. International Journal of Paediatric Dentistry 2006; 16(4): 257-262.

18. Wyne AH. Caries Prevalence, Severity, and Pattern in Preschool Children. J Contemp Dent Pract 2008 March; (9)3: 024-031.

19. Freeman R, Breistein B, McQueen A and Stewart M. The dental health status of five-year-old children in north and west Belfast. Community Dent Health 1997; 14(4): 253-257.

20. Peres MA, Dias de Oliveira Latorre MDR, Sheiham A, Peres KG, Barros FC and Hernandez PG. Social and biological early life influences on severity of dental caries in children aged 6 years. Community Dent Oral Epidemiol 2005; 33:53-63.

21. Goyal A, Gauba K, Chawla H, Kaur M and Kapur A. Epidemiology of dental caries in Chandigarh school children and trends over the last 25 years. J Indian Soc Pedo Prev Dent 2007; 25: 115-118.

22. Caameron FL, Weaver LT and Wright CM. Dietary and Social Characteristics of Children with Severe Tooth Decay. SMJ 2006; 51(3): 26-29.

23. Petersen PE and Esheng Z. Dental caries and oral health behaviour situation of children, mothers and schoolteachers in Wuhan, People's Republic of China. International Dental Journal 1998; 48: 210-216.

24. Silver DH. A comparison of 3-year-olds' caries experience in 1973, 1981 and 1989 in a Hertfordshire town, related to family behaviour and social class. British Dental Journal 1992; 172: 191 -197.

25. Denise MP, Spolidorio JF and Höfling DM. Dental caries status in deciduous and permanent dentition of Brazilian children aged 6-8 years with a socioeconomic base. Braz J Oral Sci 2003; Vol 2(4): 147-151.

26. Mdo CF, de Melo RB and Almeida e Silva S. Dental caries prevalence in relation to socioeconomic status of nursery school children in Goiânia-GO, Brazil. Community Dent Oral Epidemiol 1996; 24(5): 357-361.
27. Davies GM, Blinkhorn FA and Duxbury JT. Caries among 3-year-olds in Greater Manchester. British Dental Journal 2001; 190: 381-384.

28. Sudha P, Bhasin S and Anegundi RT. Prevalence of dentalcaries among 5-13-year-old children of Mangalore city. J Indian Soc Pedod Prev Dent 2005; 23: 74-79.

29. Al-Hosani E and Rugg-Gunn A. Combination of low parental educational attainment and high parental income related to high caries experience in pre-school children in Abu Dhabi. Community Dent Oral Epidemiol 1998; 26: 31-36.

30. Douglass JM, Yi W and Xue ZB. Dental caries in preschool Beijing and Connecticut children as described by a new caries analysis system. Community Dent Oral Epidemiol 1994; 22(2): 94-99.

31. Joanna MD, Wei $Y$ and Zhang BX. Caries prevalence and patterns in 3-6-year-old Beijing children. Community Dent Oral Epidemiol 1995; 23: 340-343.

32. Segovia A, Ramon ER and Eduardo C. Dental Caries Experience and factors among preschoolers in south eastern Mexico: A brief Communication. J Public Health Dent 2006; 66(2): 88-91.

33. Khan $\mathrm{MN}$ and Cleaton-Jones PE. Dental caries in African preschool children: social factors as disease markers. J Public Health Dent 1998; 58(1): 7-11.

34. Naidu RS and Davis L. Parents' views on factors influencing the dental health of Trinidadian pre-school children. Community Dent Health 2008; 25(1): 44-49.

35. Szatko F, Wierzbicka M and Dybizbanska E. Oral health of Polish three-year-olds and mothers' oral health-related knowledge. Community Dent Health 2004; 21(2): 175-180.

36. Wierzbicka M, Petersen PE and Szatko F. Changing oral health status and oral health behaviour of schoolchildren in Poland. Community Dent Health 2002; 19(4): 243-250.

37. Williams NJ, Whittle JG and Gatrell AC. The relationship between socio-demographic characteristics and dental health knowledge and attitudes of parents with young children. British Dental Journal 2002; 193: 651-654.

38. Tyagi R. The prevalence of nursing caries in Davangere preschool children and its relationship with feeding practices and socioeconomic status of the family. J Indian Soc Pedod Prevent Dent 2008; 26: 153-156.

39. Jose B and King NM. Early childhood carious lesion in Preschool children in Kerala, India. Pediatr Dent 2003; 25(6): 594-600. 